\title{
Myxospermous seed-mucilage quantity correlates with environmental gradients indicative of water-deficit stress: Plantago species as a model
}

\author{
António Teixeira $(\mathbb{D} \cdot$ Pietro Iannetta $\cdot$ Kirsty Binnie • \\ Tracy A. Valentine $\cdot$ Peter Toorop
}

Received: 29 May 2019 / Accepted: 3 October 2019 /Published online: 23 November 2019

(C) The Author(s) 2019

\begin{abstract}
Aims Myxospermous seed mucilage is multifunctional and is often found in seeds (or achenes) of species occupying arid environments where the trait may influence seed-dispersal and -germination of seeds. The seed mucilage may also enhance soil-water retention, -hydraulic conductivity and -stability. However, the relationship between seed mucilage quantity, seed germination and seedling traits across environmental gradients which determine water-deficit stress has not yet been ascertained.

Methods Therefore, we characterised and tested the relationship between seed mucilage quantity, water-deficit stress responses of seeds and seedlings of 36 accessions of four different Plantago species ( $P$. albicans L., $P$. coronopus L., P. lagopus L. and P. anceolata L.). These were gathered from six regions across Europe, which
\end{abstract}

Responsible Editor: Hans Lambers.

Electronic supplementary material The online version of this article (https://doi.org/10.1007/s11104-019-04335-z) contains supplementary material, which is available to authorized users.

\footnotetext{
A. Teixeira $(\bowtie) \cdot$ P. Toorop

Department of Comparative Plant and Fungal Biology, Royal Botanic Gardens, Kew, Wellcome Trust Millennium Building, Wakehurst Place, Ardingly, West Sussex RH17 6TN, UK e-mail: antonio.teixeira@bio.uminho.pt
}

\section{A. Teixeira}

Earth and Environmental Sciences Department, University of Pavia, via S. Epifanio 14, 27100 Pavia, Italy presented environmental gradients (of rainfall and temperature), and varying soil qualities.

Results Seed mucilage was significantly greater in seeds of accessions experiencing: highest summer temperatures; lowest summer precipitation; soils of the same warm dry regions which had greater capacity to retain water within narrow pore spaces. Under water-deficit stress, seeds with most mucilage exhibited a lower base water potential for germination, suffered least seedling mortality and exhibited the most successful seedling development.

Conclusions The findings indicate that seed mucilage quantity appeared as an 'adaptive' trait and there is a relationship between seed-mucilage quantity, seed germination plus seedling survival and development under environmental conditions of highest water-deficit stress.

\author{
P. Iannetta $\cdot$ K. Binnie $\cdot$ T. A. Valentine \\ Ecological Sciences, James Hutton Institute, Invergowrie, \\ Dundee, Scotland DD2 5DA, UK
}

\author{
Present Address: \\ A. Teixeira \\ Centre of Molecular and Environmental Biology (CBMA), \\ University of Minho, Braga, Portugal
}


Keywords Myxospermy · Seed · Water-deficit · Soil · Plantago

\section{Introduction}

A shortage of plant available soil water can severely limit plant growth and development, particularly in arid and semi-arid regions (Xu et al. 2010). Consequently, the response characteristics of plants exposed to drought (water deficit) stress has become an important environmental-research topic. Seed germination and early seedling growth are critical transition life-history stages at which water deficit stress can be problematic (Ahmad et al. 2009). During these early "life" seeds and seedlings are often exposed to seasonal weatherextremes and -stochasticity and so present especially vulnerable life-history stages.

In campo, soil water content increases after rainfall and then decreases as the soil drains under gravity and dries by evapotranspiration, leading to a continual fluctuation in soil matric potential (sMP) and soil strength at any given location (Bengough et al. 2011). The flow of water from the soil to plant roots is controlled by the properties of the narrow region of soil close to the roots, including the soil pore space and rhizosphere. In particular, the hydraulic properties of the rhizosphere are altered by mucilage, a polymeric gel exuded by the roots. McCully and Boyer (1997) reported that mucilage loses most of its water at water potentials lower than $-0.01 \mathrm{MPa}$ and concluded that root mucilage water content, per se does not play a significant role in plant drought protection. However, subsequent reports provided conceptual and experimental evidence that root mucilage does have a strong impact on soil water dynamics (Kroener et al. 2014), increasing the water content in the rhizosphere at any water potential (Carminati et al. 2010), and facilitating the water flow from dry soils towards the root surface (Ahmed et al. 2014).

The capacity of seeds to be enveloped in a mucilage sheath upon hydration is known as myxospermy, and this trait occurs in a broad range of plant families, from the Acanthaceae and the Brassicaceae, to the Linaceae and the Plantaginaceae (Western, 2012). Production of seed mucilage is an ecologically important trait that facilitates successful establishment of plants in diverse habitats, and thus it may be an adaptation to arid, ruderal and disturbed environments (Yang et al. 2010). Most studies have focused on the role of mucilage as a seed anchoring mechanism and in germination. This is due to the adhesive capacities of the mucilage, anchoring the seed to the soil surface, assisting seedling establishment by lubricating the radicle as it penetrates the soil (Schat 1981; Lobova et al. 2003). Therefore, the seed mucilage is multi-functional ecologically. The adaptive benefit of seed mucilage production has been confirmed for Artemisia annua and A.biennis in disturbed areas, Neopallasia pectinata in semiarid areas (Cullen 1975; Kreitschitz and Vallès 2007) and Lepidium flavum, L. nitidum, Plantago lanceolata, Cardaria draba and Arabidopsis thaliana in ruderal habitats (Young and Evans 1973; Western et al. 2000).

Myxospermous seed mucilage has long been proposed to promote seed germination through attraction and retention of water surrounding the seed (Harper and Benton 1966; Fahn and Werker 1972; Young and Martens 1991; Huang and Gutterman 2000; Penfield et al. 2001). This capacity is a function of the seed mucilage's low osmotic potential $(-0.54 \mathrm{MPa})$, which enables it to absorb a weight of water that is up to $16^{\times}$ the mucilage dry weight in shepherd's purse (in Capsella bursa-pastoris L. Medik, shepherd's purse; Deng et al. 2011). The impact of myxospermous seeds on soil physical properties was also studied using the myxospermous seeds of shepherd's purse as a model (Deng et al. 2014). These authors studied how specifically the relative capacity of myxospermous seeds, the seed mucilage alone and non-myxospermous seeds affect the physical behaviour of a soil, reporting that myxospermous seeds had greater capacity to enhance soil-water retention, -hydraulic conductivity and stability.

In this study myxospermous seed from four ruderal herbaceous Plantago species were characterised. Plantago was chosen due the adaptation of the seeds to arid and low nutrient soil environments. The species are found localised in largely distinct pedoclimates and these species are: $P$. albicans, which has a perennial or annual life cycle and a Mediterranean distribution; $P$. lagopus, which is an annual or less frequently perennial herbaceous habit living in similar Mediterranean environments; P. coronopus, which is a perennial or less frequently biennial or annual with common distribution in occidental Europe; and, P. lanceolata, a perennial plant with a Eurasia distribution (Castroviejo et al. 2009). For each species, seed mucilage quantity was characterised for germination and seedling development using control and water-deficit conditions, the latter 
administered using osmoticum. Representative soil samples from the pedoclimate of each species were also collected and characterised for the hydrological properties of soil-water retention and -strength. Our approach assessed the relationship between the seed mucilage quantity, seed and seedling characteristics in response to control and water-deficit conditions and maternal climatic and soil conditions. The null hypotheses being tested are that seed mucilage quantity; (1) is not related to the pedoclimatic of its niche-space or locality; and (2), does not facilitate seed germination or seedling survival and development under conditions of waterdeficit.

\section{Material and methods}

Plant material

Seeds from four species (P. albicans, P. coronopus, $P$. lagopus, and P. lanceolata) were collected from 50 to 200 plants per accession in 2015. In this way, a total of 36 accessions were collected in six regions which covered four countries: Andalusia (An, Spain); Asturias (As, Spain); Canary islands (Ci, Spain); Minho/Trás-osMontes (MT, Portugal); Arles-Provence-Alpes-Côte d'Azur (Ar, France); and, Newhaven-Sussex (Ne, UK). For each species, the accessions were sampled at the time of natural dispersal (Table S1). Upon collecting, all accessions were cleaned, dried and kept in a controlled environment $\left(15^{\circ} \mathrm{C}, 15 \% \mathrm{RH}\right)$ until germination experiments (less than 12 months). For each accession site (except Ar and two An accessions) a single soil sample was collected $(0-10 \mathrm{~cm}$ depth), stockpiling different samples for each pedoclimate.

\section{Soil water retention curves}

To study the soil pedoclimatic attributes and waterdeficit stress on seed germination and seedling development, soil water retention curves (SWRC, Watson 1966) were obtained from the soil samples collected at each seed-collecting site. Briefly, triplicate sub-samples were air dried until less than $20 \%$ gravimetric moisture content ( $\mathrm{gMC}$ ) was reached, then each was sieved using a $3 \mathrm{~mm}$ sieve. $10 \mathrm{~g}$ of each of the three replicate subsamples were placed in sealed plastic bags after gMC was adjusted to $20 \% \pm 0.3$ and these were stored overnight to allow moisture to equilibrate. Previously weighed plastic soil cores with porous bases made of nylon fabric held in place with an elastic band were packed with the soil amount to fill the core volume $\left(19.1 \mathrm{~cm}^{3}\right.$; mean dry bulk density (DBD) of $1.21 \pm$ $0.13 \mathrm{~g} . \mathrm{cm}^{3}$ ), and then fully hydrated overnight and weighed. Each core was subjected to suctions ranging from -1 to $-1500 \mathrm{kPa}$ using a tension table ( -1 to $-50 \mathrm{kPa}$; Soil moisture Equipment Corp, USA) and pressure plate ( -50 to $-1500 \mathrm{kPa}$; Soilmoisture Equipment Corp, USA), then finally dried in an oven at $105^{\circ} \mathrm{C}$ for $48 \mathrm{~h}$ to measure the final dry weight of soil. Each core was weighed at each transfer stage. The SWRC curves were plotted against the $-\mathrm{kPa}$ suction values. The logarithmically transformed $\left(\log _{10}\right) \mathrm{sMP}-\mathrm{kPa}$ values $(-5$ to $-300 \mathrm{kPa}$ ) values (independent variable; $x$-axis) were linearly regressed against the response variable gravimetric moisture content (gMC; $y$-axis). Examining the difference between soil gMC at the upper and lower limits determines the water volume held in pore spaces of specific diameters (see also Valentine et al. 2012).

Soil penetration resistance

Soil penetration resistance (sPR) tests were carried out in each soil core using a penetrometer (Instron model 5544; Instron, MA, USA) at three $\operatorname{sMPs}(-5 \mathrm{kPa}$, $-20 \mathrm{kPa}$ and $-300 \mathrm{kPa})$, using a $1 \mathrm{~mm}$ diameter $30^{\circ}$ angle cone at a constant penetration rate of $4 \mathrm{~mm} \cdot \mathrm{min}^{-1}$ from 5 to $15 \mathrm{~mm}$ depth (Bengough and Mullins 1990, 1991). The logarithmically transformed $\left(\log _{10}\right)$ sMP $\mathrm{kPa}$ values ( -5 to $-300 \mathrm{kPa}$ ) (independent variable; $x$ axis) were linearly regressed against the response variable soil penetrometer resistance values (sPR; $y$-axis).

Seeds mucilage weight determination

To evaluate the contribution of mucilage quantity of each species germination and seedling development, triplicates of ten seeds for each of the 36 accessions, previously oven-dried overnight $\left(105^{\circ} \mathrm{C}\right)$ and weighed, were incubated with $10 \mathrm{~mL}$ of cellulase enzyme (Celluclast $^{\mathrm{TM}}$, Novozymes, Sigma Aldrich, Gillingham, United Kingdom) at $12 \%[\mathrm{v} / \mathrm{v}]$ concentration solution $\left(\mathrm{pH}=5.5\right.$ ) for $72 \mathrm{~h}$ at $50^{\circ} \mathrm{C}$ with gentle shaking. The effectiveness of the treatment was checked using a light microscope after staining the seeds with ruthenium red to detect any remaining mucilage (Sigma Aldrich, Gillingham, United Kingdom) (McFarlane et al. 2014). The digested seeds were washed three times with $15 \mathrm{~mL}$ of 
Milli-Q® water (Merck Millipore, Watford, United Kingdom) to remove the cellulase, oven dried at $70^{\circ} \mathrm{C}$ for $3 \mathrm{~d}$ and weighed. The mucilage quantity was obtained from the difference of the seed weight before and after digestion and is expressed as percentage of seed dry weight.

\section{Climatic conditions}

To characterise each location from which the plant accessions were gathered we obtained the climatological conditions by cross-referencing our geographic localities with the WORLDCLIM database (Hijmans et al. 2005) using DIVA-GIS software (Hijmans et al. 2004). Using the obtained interpolated climatological data we obtained the mean of the minimum precipitation that occurred in the driest month (July) and the mean of the maximum temperatures that occurred in the hottest month (July) for the period 1950 to 2000 (Hijmans et al. 2005). A map of the pedoclimatic collecting sites was made (Qgis Version 2.10.1) using The Environmental Stratification of Europe dataset (Metzger 2018). The gradient colour of the dots, representing the collecting sites relate to the first dimension of the Principal component analysis (PCA) of the above climatological conditions (Package FactoMineR Version: 1.36).

Seed germination and seedling development experiments

To determine the factorial effect of temperature- and water-deficit stress on seed germination and seedling development, seed from a sub-set of 25 accessions was used. Germination tests on osmoticum were performed using three independently replicated experiments, and the osmotic-strength of the solutions ranged from 0 , $-0.2,-0.4,-0.6$ and $-0.8 \mathrm{MPa}$ (i.e. five treatments). Seeds were incubated at $15^{\circ} \mathrm{C}$ or $20^{\circ} \mathrm{C}$. Within each experiment, each osmotic solution (treatment) was applied in triplicate and prepared according to equation (Bengough 1990) in the manuscript by Hardegree and Emmerich (1990):

[1] 0.129[PEG] $]^{2} \mathrm{~T}-14.0[\mathrm{PEG}]^{2}-0.40[\mathrm{PEG}]$.

Where $\mathrm{T}$ is the germination temperature, and PEG is Polyethylene glycol 8000 (Sigma Aldrich, Gillingham, United Kingdom).
Thus: across the five osmotic treatments, seeds from each of 25 accessions were tested using three Petri dishes plates (each containing 50 seeds) at the two temperatures. That is $((5 \times 25) \times 3) \times 2)=750$ dishes for each germination experiment, and each experiment was performed three times.

The Petri dishes were placed on trays ( 75 per tray), within sealed plastic bags to avoid any confounding effects of dehydration. Seed germination (accounted when radicle $>1 \mathrm{~mm}$ ), was scored daily for 5 weeks (until germination was no longer observed in any treatment). Germinated seeds were carefully transferred to germination paper (Whatman ${ }^{\mathrm{TM}}$, grade 1, \#1001-824), pre- moistened with $15 \mathrm{~mL}$ of the same osmotic solution and held within transparent re-sealable plastic boxes $(17 \times 12 \times 5 \mathrm{~cm})$. This was also then resealed into a plastic bag as before. Seedling growth was observed every $3 \mathrm{~d}$, until the opening of the cotyledons into true leaves (until a maximum of $34 \mathrm{~d}$ after germination). In total, 10,537 seedlings were observed in this way. At the end of the test-period, seeds which had failed to germinate were cut open and classified by appearance as viable or dead depending of embryo presence/absence.

Germination percentages were calculated as the number of seeds germinated as a percentage of the total germinated seeds plus those that did not germinate but that were scored viable. Successful "seedling development" was scored as the percentage of seeds that reached cotyledon opening of the total number of seeds germinated. Seedling mortality percentages were calculated as the percentage of seeds that germinated but failed to reach cotyledon stages. These seedlings eventually developed infection and perished.

Statistical analysis

All statistical tests were performed using the R environment with version R3.3.3, Core Team 2016 except the sigmoidal curve fit (Origin software, OriginLab, Northampton, MA, USA).

Gravimetric moisture content (gMC) and soil penetrometer resistance $(\mathrm{sPR})$, at $-300 \mathrm{kPa}$ of sMP, were regressed against Latitude and Longitude collecting references; similarly maximum temperature and minimum precipitation were regressed against $\mathrm{SPR}$ and $\mathrm{gMC}$ values.

The effect of temperature on germination and seedling development in the osmoticum range was visualised with boxplots and differences were analysed using 
Generalized Linear Mixed Models (Package lme4, Bates et al. 2014) with binomial distribution family and logit link with germination and seedling proportions as response variables; species, temperature and osmoticum as fixed effects (and factors) and with the Latitude and the Longitude as random effects.

A Factor Analysis of Mixed Data (FAMD) (Package FactoMineR Version: 1.36) was performed for each condition and temperature with species and collecting region as categorical variables, the mean of the final germination or seedling development as numerical variables and with Maximum temperature, Minimum precipitation, gMC and sPR at $-5 \mathrm{kPa}$ and $-300 \mathrm{kPa}$ as supplementary variables. Generalized Linear Models (GLM) with Gaussian distribution and identity link were performed to test the effect of pedoclimate conditions of the collecting sites (Maximum temperature; Minimum precipitation.; gravimetric soil water content) and soil penetrometer resistance on the two FAMD principal dimensions.

Subsequently, Akaike information criterion (AIC) was used for models simplification step-wise deletion of non-informative parameters, until a minimum adequate model for each case was selected.

Significant variables of the FAMD second dimension of each model were visualised with the function type = “eff” (Package sjPlot, Version: 2.4.1).

Differences in species seed mucilage quantity (Mq) were obtained with one-way ANOVA and Tukey's multiple comparisons test. Regional differences on mucilage quantity were obtained with a GLM model choosing the Andalusia region as intercept. The mucilage quantity was regressed against the daily minimum precipitation occurring in the driest month and the daily maximum temperature occurring in the hottest month. To test how the mucilage correlates with germination and seedlings development, FAMDs of germination and seedlings development values were performed for each temperature, as above, but with seed mucilage quantity as supplementary variable. Similarly and to evaluate how mucilage correlates with germination mortality, FAMDs of germination mortality in both temperatures were performed after the missing values were obtained with the imputeFAMD function (Package missMDA, version 1.11; Josse and Husson 2016), excluding the $-0.8 \mathrm{MPa}$ values.

GLM models were performed to test the effect of seeds mucilage quantity (Mq) on gravimetric water present in the soil small pore spaces (sgMC) with Mq, species and the interaction sgMC: species as predictor variables. Similar models were performed to test the difference of soil gravimetric water content at $-5 \mathrm{kPa}$ and $-300 \mathrm{kPa}(\Delta \mathrm{gMC}-5 \mathrm{kPa}:-300 \mathrm{kPa})$, with $\mathrm{Mq}$ and its interaction with species as predictor variables.

To evaluate the effect of seeds mucilage quantity on germination and seedling development, GLM models with Gaussian distribution and identity link were undertaken for each osmotic condition and temperature. The same procedure was used to test the mucilage effect on the germination mortality using the untransformed values.

For each accession the germination rate (GR) was inferred from the reciprocal of the time to $50 \%$ germination, estimated through a sigmoidal curve fit of the cumulative germination for each dish using the Boltzmann equation (Toorop et al. 2011). With the range of osmoticum of each replicate experiment per accession, the GRs were regressed with a linear model, to estimate the base water potential at which the germination rate was equal to zero $\left(\Psi_{\mathrm{b}} \mathrm{G}\right)$. Similarly, seedling base water potentials $\left(\Psi_{\mathrm{b}} \mathrm{S}\right)$ were estimated. Generalized Linear Models (GLM) with Gaussian distribution and identity link were performed to test the effect of seed mucilage quantity on $\Psi_{\mathrm{b}} \mathrm{G}$ and $\Psi_{\mathrm{b}} \mathrm{S}$ accessions.

\section{Results}

Soil gravimetric water content and soil strength are influenced by weather conditions of collecting sites

To help characterise the localities from which the plant accessions were gathered (Fig. 1a, b), the climatic and geographical positional data (Fig. S1 and Table S1) were related to soil data (gMC and PR as a measure of soil strength; Table S2). The soil matric potential (sMP, from -0.01 to $-1500 \mathrm{kPa}$ ) showed that average gMC values were significantly different between Minho/Trás-osMontes (MT) and Andalusia (An) regions from $-20 \mathrm{kPa}(p<0.024)$ to $-300 \mathrm{kPa}(p<0.000)$. Soil water availability at an sMP of $-300 \mathrm{kPa}$ is an indicator of water which is difficult for plants to take up. At this sMP the upper limit of soil water availability ranged over three-fold, from a minimum of $0.09 \mathrm{~g} \mathrm{~g}^{-1}$ in MT to a maximum of $0.33 \mathrm{~g} \mathrm{~g}^{-1}$ in An collecting region (Table S2). Therefore, to assess the extent to which water may be easily available to the plant we examined the difference between soil $\mathrm{gMC}$ at -5 and $-300 \mathrm{kPa}$ 
Fig. 1 Gravimetric soil moisture content (gMC) [g.g $\left.{ }^{-1}\right]$ and soil penetrometer resistance (sPR) (MPa) measured under suction ($\mathrm{kPa})$. Where: a $\mathrm{gMC}$ as function of the sMP $(-5,-20,-50$ and $-300 \mathrm{pKa}$ ) with the $x$-axis value expressed as logarithm $\left(\log _{10}\right) ; \mathbf{b}$ sPR measured under sMP ( -5 , -50 and $-300 \mathrm{kPa}$ ) with the $x$-axis value expressed as logarithm $\left(\log _{10}\right)$. gMC $(-300 \mathrm{kPa})$

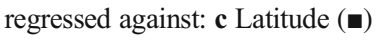
and Longitude $(\circ ; F=4.416 ; P=$ 0.044 ; dashed line) at SPR $(-300 \mathrm{kPa})$ : d Latitude $(\bullet ; F=$ $-16.32 ; P<0.000$; solid line), and Longitude (O); e maximum temperature $(\boldsymbol{\nabla} ; F=14.75$;

$P<0.000$; solid line), and precipitation $(\nabla ; F=20.46 ; P<0.000$; dashed line). Correlations were performed with the mean of three replicates for each condition except weather conditions
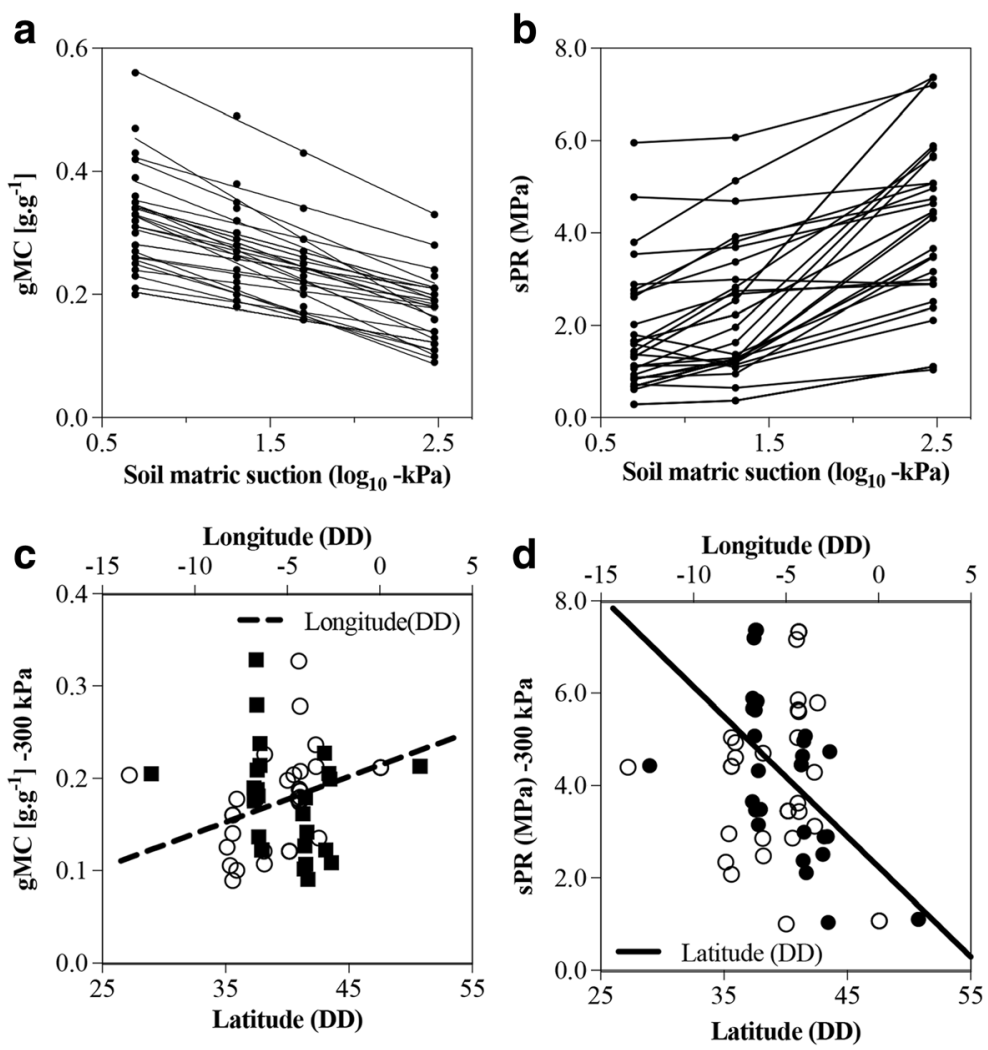

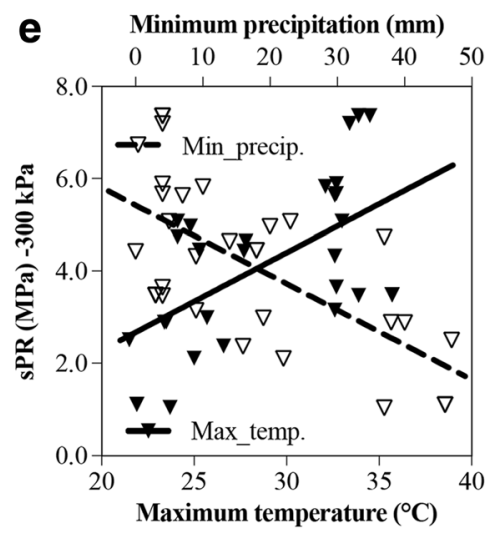

SMP as these upper and lower limits represents the suction pressure required to extract water from relatively large soil pore space diameters ranging from 60 to $1 \mu \mathrm{m}$, respectively, and determines the water volume held in pore spaces which are of intermediate diameter. Soils from collection sites in Newhaven $(\mathrm{Ne})$ demonstrated greater water storage potential $\left(0.77 \mathrm{~g} \mathrm{~g}^{-1}\right)$ within pore spaces of these intermediate diameters followed by Andalusia $\left(0.73 \mathrm{~g} \mathrm{~g}^{-1}\right)$, while the lowest storage potential $\left(0.33 \mathrm{~g} \mathrm{~g}^{-1}\right)$ was observed in Portugal (Table S2). To summarise, source soils differed significantly in their capacity to hold water, and for that water to be accessed by plants. Also, water was more strongly held in harder soils from more southerly and westerly locations (Fig. 1c, d and e, Table S2). That is, these southwesterly soils exhibited a higher volume of smaller pore spaces with reduced free-drainage potential, and rainfall is also less in those pedoclimates. Linear regressions also showed significant negative soil penetrometer resistance correlation with Latitude $(F=-16.32$; $P<0.000$; Fig. 1d). This allowed us to define mathematically the relationship already described, which is: 
that soil demonstrating greater penetrometer resistances (harder soils) were found in southerly and westerly locations. Describing the data with respect to climatic variables (max. temperature and min. precipitation), confirmed this: soils with higher PR were found in regions which experience lower rainfall and warmer ambient temperatures (Fig. 1e; $F=20.46 ; p<0.000$; and, $F=14.75 ; p<0.000$, respectively). The southern collecting regions showed lower values of minimum precipitation than northern regions (29 and $4 \mathrm{~mm}$ respectively) in the driest month. The maximum temperatures observed in the hottest month were higher in the southern than northern regions $\left(33\right.$ and $24^{\circ} \mathrm{C}$ respectively; Table S1). Thus, harder soils showing greater penetrometer resistances had been exposed to lower minimum precipitation and higher maximum temperatures.

Mucilage quantity significantly varies between species and correlates with environmental conditions of collection site

The quantity of mucilage (Mq) associated with seed of the four different species varied significantly, with seeds of $P$. albicans yielding most mucilage, followed by P. coronopus, P. lagopus and P. lanceolata with mucilage accounting for 33, 29, 26 and $12 \%$ of the seed dry weight, respectively (Fig. 2a). Tests of the relationship between $\mathrm{Mq}$ and locality of the maternal source found that accessions from MT and Asturias (As) showed significantly less mucilage content than those from An region (Fig. 2a and Table S3). Seed mucilage quantity of the individual accessions correlated negatively with the minimum precipitation $(F=7.209$; $p=0.011)$ and positively with the maximum temperature $(F=6.782 ; p=$ 0.014 ) that occurred in each collecting site (Fig. 2b). Thus, seed with higher mucilage quantity originated from sites exposed to lower precipitation and higher temperature environments.

GLMs were used to test the relationship between: (1) $\mathrm{Mq}$ and the volume of pore space which does not hold water strongly ( $\Delta \mathrm{gMC},-5 \mathrm{kPa}:-300 \mathrm{kPa})$, and (2), the proportion of pores of intermediate size (or less), from which plants would have difficulty extracting water $(\mathrm{sgMC}-300 \mathrm{kPa} /-5 \mathrm{kPa})$. This showed that seed mucilage quantity is lower when soil pore spaces are larger (holding water weakly; Fig. 2c and Table S4). Seed mucilage quantity was also significantly greater where the proportion of small soil pore spaces accounted for a greater proportion of total pore space, i.e. seeds have more mucilage for accessions found growing in soils where water was held more strongly (Fig. $2 \mathrm{~d}$ and Table S4).

Effect of temperature and water-deficit stress on seed germination and seedling development

GLMM test models of osmoticum on seed germination showed that $\%$ germination was significantly lower at $20^{\circ} \mathrm{C}$ compared to $15^{\circ} \mathrm{C}$ and lower at increasing osmotic strengths compared with $0.0 \mathrm{MPa}$. A positive effect was observed on germination in the interaction of temperature with osmoticum at -0.2 and $-0.4 \mathrm{MPa}$ (Fig. S2a and Table S5). In contrast, the proportion of developed seedlings did not differ significantly between these two temperatures. Compared to P. albicans, more $P$. coronopus seedlings developed at $20^{\circ} \mathrm{C}$ than at $15^{\circ} \mathrm{C}$, while less seedlings of $P$. lagopus and P. lanceolata developed at $20^{\circ} \mathrm{C}$ than at $15^{\circ} \mathrm{C}$ (Fig. S2b and Table S5). This indicates that a higher temperature $\left(20^{\circ} \mathrm{C}\right)$ has a greater negative effect on Plantago seed germination than seedling development. Seedling development was strongly affected by high osmotic strength, and for most osmotic solutions a positive interaction was observed with temperature for all MPs strengths (Fig. S2b and Table S5). In addition, $P$. coronopus is highlighted as a species with higher levels of tolerance to higher temperatures and osmoticum during seedling development.

Links between soil pedoclimatic attributes and water-deficit stress on seed germination and seedling development

The first dimension in the FAMD analysis explained more than $37 \%$ of the germination data/variability (regardless of incubation temperature), and the $\%$ germination tended to decrease with increasing Longitude (Fig. S3a, b, c and d). The second dimension explained more than $17 \%$ of the variability (regardless of incubation temperature), due to the water stress deficit (osmotic) treatment, and \% germination tending to increase as osmotic stress decreased.

The first dimension in the FAMD for seedling development explained more than $28 \%$ of the variability (regardless of incubation temperature), with a distinct clustering of the species. The second dimension explained more than $16 \%$ on the basis of water stress deficit (osmotic) treatment, with $\%$ seedling 
Fig. 2 Seed mucilage quantity of 36 accessions in \% of dry weight (DW). a The mucilage quantity (\% of the seed DW) of four Plantago species; b Regression analysis of seed mucilage quantity against the mean of the maximum temperature $(\boldsymbol{\nabla} ; F=$ $6.78 ; P=0.014$; solid line) that occurred in the hottest month $\left({ }^{\circ} \mathrm{C}\right)$ and the mean of precipitation $(\nabla$; $F=7.11 ; P=0.011$; dashed line) that occurred in the driest month $(\mathrm{mm}) ; \mathbf{c}$ GLM regressions (Table S4), testing the effect of seeds mucilage quantity of the different species on soil water available $(\triangle \mathrm{gMC})$; $\mathbf{d}$ soil small pores (sgMC) water content values. The analyses were performed with the mean of three replicates for each species accession
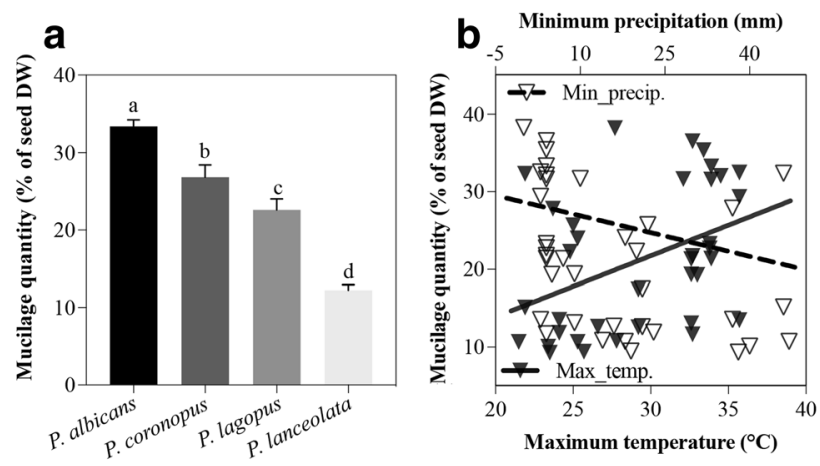

$$
\text { c }
$$

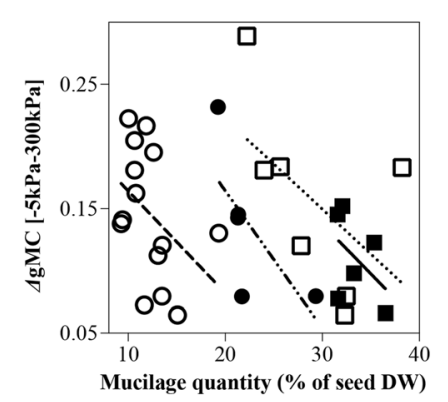

development tending to increase as water-deficit stress decreased (Fig. S3e, f and h). The additional variables gMC, sPR and Longitude showed the highest correlation values in both germination and seedling development (Fig. S3e and g).

GLM models, testing the effect of pedoclimate variables on the FAMD's second dimension, showed that germination at $15^{\circ} \mathrm{C}$ was influenced positively by the pedoclimate variables temperature (Max_Temp), precipitation (Min_Precip) and soil strength (sPR_300kPa) but not by gravimetric moisture content (gMC_300kPa) (Fig. 3a, b and c, Table S6). On the other hand, the same pedoclimate variables negatively influenced the germination at $20^{\circ} \mathrm{C}$ (Fig. 3d, e and f, Table S6). The effect of pedoclimatic variables on seedlings development was similar to germination at $20^{\circ} \mathrm{C}$ (Fig. $3 \mathrm{~h}$, i and j, Table S6). Only Max_Temp had negative effects on seedlings development at $15^{\circ} \mathrm{C}$ (Fig. $3 \mathrm{~g}$ and Table S6).

Effect of mucilage quantity on seed germination and seedling development

FAMD analysis indicates that $\mathrm{Mq}$ is not correlated with $\%$ germination at the lower $\left(15^{\circ} \mathrm{C}\right)$ germination temperature (Fig. S4a and b). However, at $20^{\circ} \mathrm{C} \mathrm{Mq}$ is positively correlated with $\%$ germination (Fig. S4c and d).
At both temperatures $\mathrm{Mq}$ is positively correlated with seedling development (Fig. S3e, f, g and h) and negatively correlated with seedling mortality (Fig. S4i, j k and 1). That is, high levels of seed mucilage enhanced seedling development and lowered seedling mortality.

At $20^{\circ} \mathrm{C}$, GLM tests showed that Mq was positively correlated with $\%$ germination at most osmotic strengths, except at $0.0 \mathrm{MPa}$ i.e. when no water deficit stress was imposed, and at $-0.6 \mathrm{MPa}$ by a small margin (Fig. 4b and Table S7), indicating a positive role of mucilage at higher temperature and water deficit stress. Significant positive correlations between $\mathrm{Mq}$ and seedling development were also observed when osmotic pressures (water deficit stress) were more negative than $0.0 \mathrm{MPa}$, and particularly at $20^{\circ} \mathrm{C}$ (Fig. $4 \mathrm{c}$ and $\mathrm{d}$ and Table S7). In addition, Mq was also negatively correlated with seedling mortality at both experimental temperatures (at osmotic pressures lower than $0.0 \mathrm{MPa}$ ), except $-0.8 \mathrm{MPa}$ (Fig. $4 \mathrm{e}$ and $\mathrm{f}$ ). Overall, this indicates that $\mathrm{Mq}$ improves a seed's capacity to germinate and survive to the fully developed seedling stage particularly where a water deficit stress is encountered.

GLMs testing the effect of seed mucilage quantity in the germination base water potential $\left(\Psi_{\mathrm{b}} \mathrm{G}\right)$ showed a negative effect at $20^{\circ} \mathrm{C}$, but not at $15^{\circ} \mathrm{C}$ indicating that myxospermous seeds with more mucilage may also 
Fig. 3 GLM models effect of pedoclimatic conditions on germination and seedlings development incubated at $15^{\circ} \mathrm{C}$ and $20^{\circ} \mathrm{C}$ FAMD's second axis scores. a Maximum temperature at $15^{\circ} \mathrm{C}$ germination; Minimum precipitation at $15^{\circ} \mathrm{C}$ germination; c soil penetrometer resistance $(-300 \mathrm{kPa})$ at $15^{\circ} \mathrm{C}$ germination; d Maximum temperature at $20^{\circ} \mathrm{C}$ germination; e Minimum precipitation at $20^{\circ} \mathrm{C}$ germination; f soil penetrometer resistance $-300 \mathrm{kPa}$ at $20^{\circ} \mathrm{C}$ germination; $\mathbf{g}$ Maximum temperature at $15^{\circ} \mathrm{C}$ seedlings; h Maximum temperature at $20^{\circ} \mathrm{C}$ seedlings; $\mathbf{i}$ Minimum precipitation at $20^{\circ} \mathrm{C}$ seedlings; $\mathbf{j}$ soil penetrometer resistance $(-300 \mathrm{kPa})$ at $20^{\circ} \mathrm{C}$ seedlings

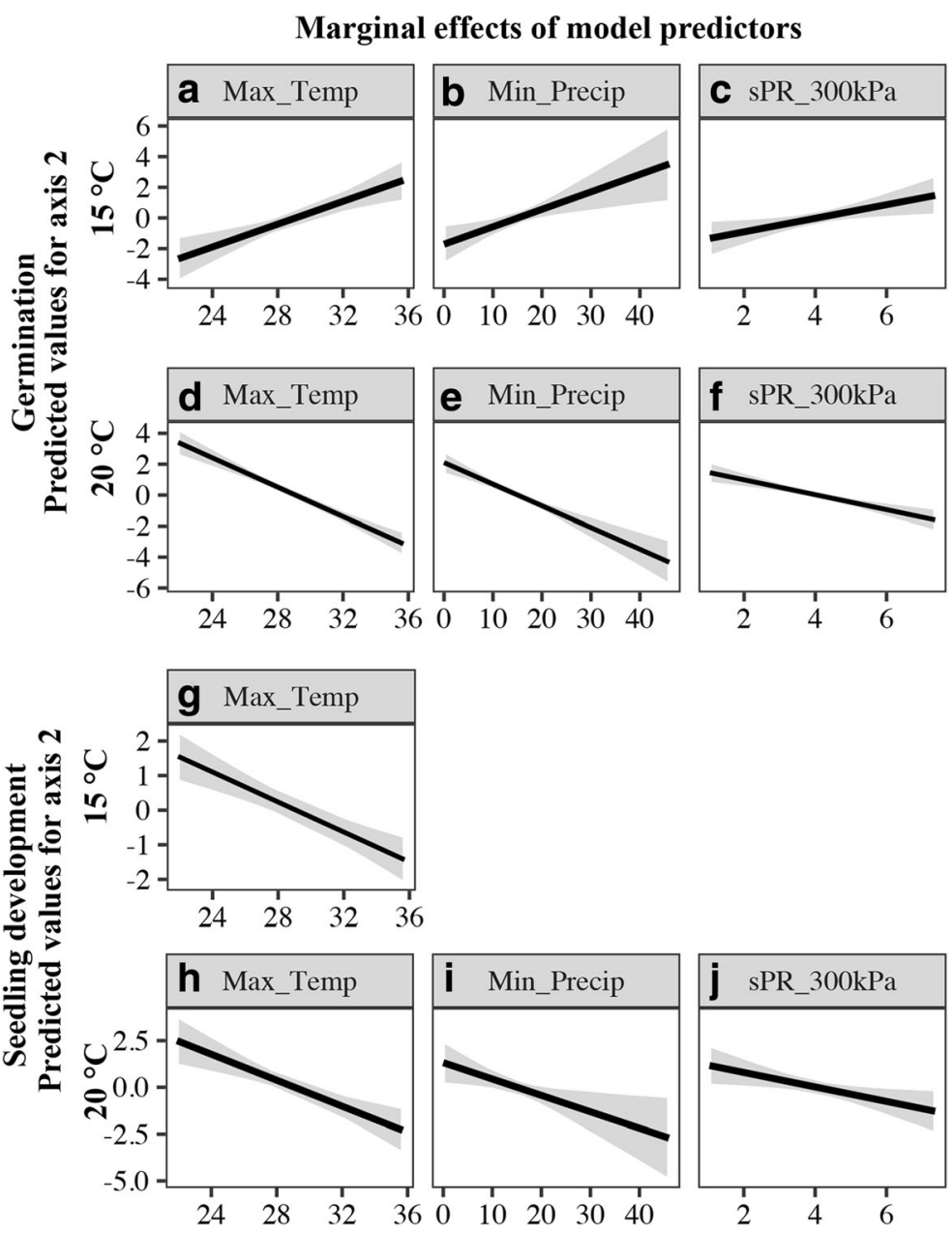

contribute more significantly to the seed \% germination under water deficit stress at higher temperatures (Fig. 5a and Table S8). However, the mucilage quantity showed no effect on the seedling development base water potential $\left(\Psi_{\mathrm{b}} \mathrm{S}\right)$ at both experimental temperatures (Fig. $5 \mathrm{~b}$ and Table S8).

\section{Discussion}

Our results have reconfirmed that seed mucilage quantity is an important trait for germination (Yang et al. 2010), and established that the role of the seed mucilage is significant for both initial germination and initial root elongation. Additionally, the amount of mucilage is associated with the species tested and significantly correlated with environmental conditions such as negative with minimum precipitation and soil hydraulic properties at field capacity, and positively correlated with maximum temperature and soil moisture. Koocheki et al. (2009) demonstrated that Alyssum homolocarpum seed mucilage exhibited non-Newtonian (pseudoplastic) behaviour, decreasing the viscosity and pseudoplasticity under increasing temperatures. This indicates that the mucilage quantity and features may be a function of environmental conditions rather than the species per se. However, the species tested did also differ significantly in the quantity of seed mucilage (Fig. 2a). P. lagopus is the only species studied that is circumscribed to the Mediterranean. This indicates higher adaptation to arid environments and consequently higher amount of mucilage production, although $P$. albicans and $P$. coronopus quantity was higher, supporting mucilage quantity as a function of environmental conditions. 


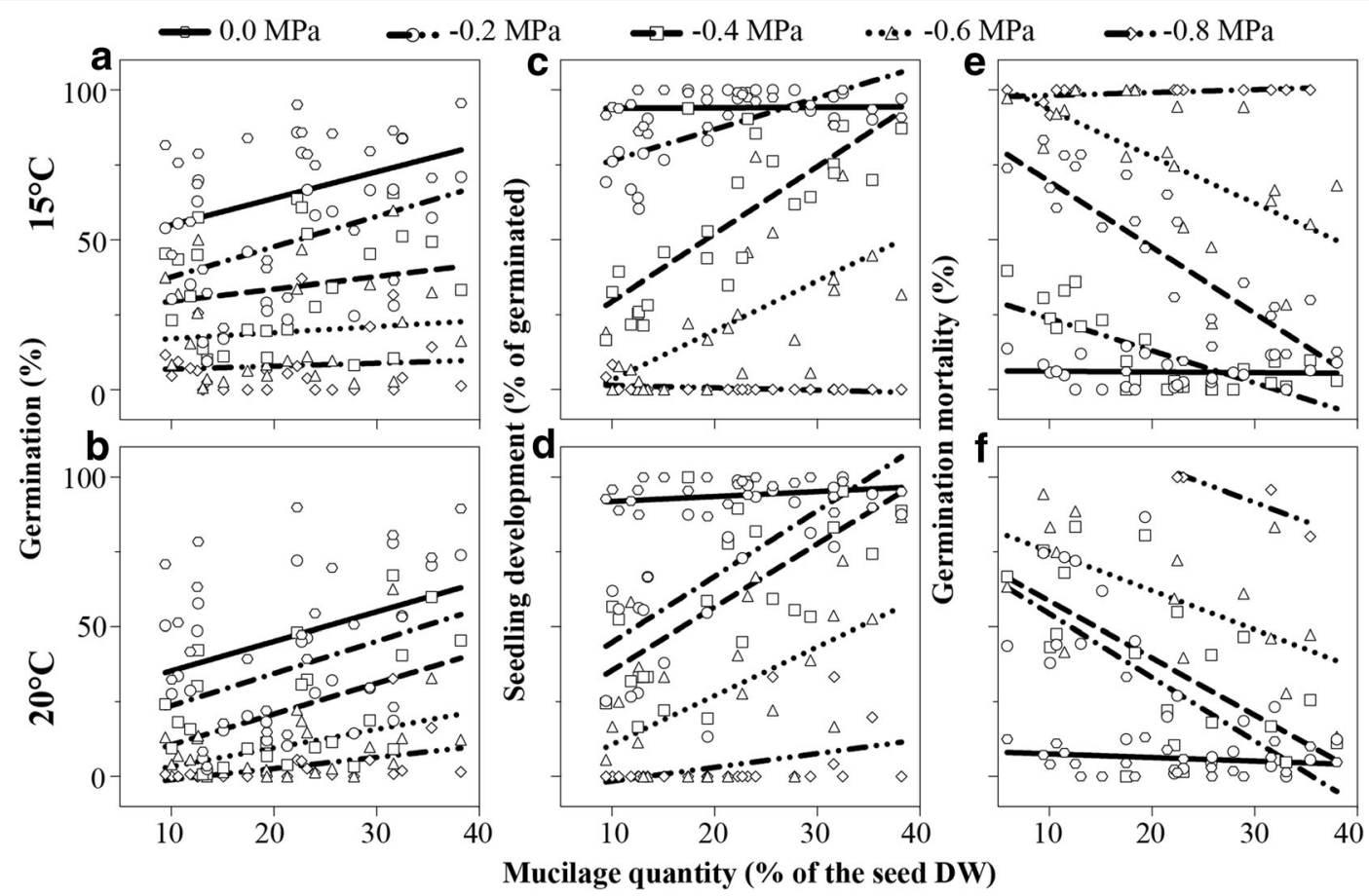

Fig. 4 GLM model of germination, seedling development and germination mortality [four species; 25 accessions in two temperature $\left(15^{\circ} \mathrm{C}\right.$ and $\left.20^{\circ} \mathrm{C}\right)$ incubations in the experimental osmoticum range]. $\mathbf{a}$ and $\mathbf{b}$ Seed mucilage effect on germination; $\mathbf{c}$ and $\mathbf{d}$ Seed

The quantities of mucilage recorded, and particularly for P. lagopus, are similar to that seen for other ruderal species, e.g. shepherd's purse in which the mucilage accounts for $25 \%$ of the dry seed weight (Deng et al. 2011). The highest amounts occur in accessions from localities with low precipitation and higher summer temperatures indicating a species-specific adaptation to the prevailing environmental and more arid conditions (Fig. 2a, Table S2 and S3). Our results indicate an mucilage effect on seedling development; e and $\mathbf{f}$ seed mucilage effect on germination mortality. GLM models were performed with the mean of three replicates for each accession for each species

overall influence of mucilage quantity in obtaining water from soil, where water availability from precipitation was low, as revealed by accessions/species that have developed more mucilage (Fig. $2 b$ and d). These areas also have soils that tend to have a higher soil strength at the dryer end of the sMPs tested, therefore the accession/ species would be more likely to be exposed to higher temperatures, drought conditions and higher soil strength conditions (Fig. 1c, d and e). This agrees with
Fig. 5 GLM model regressions of mucilage quantity effect on water base $\left(\Psi_{\mathrm{b}}\right)$. a Mucilage quantity effect on germination water base $\left(\Psi_{\mathrm{b}} \mathrm{G}\right)$ in $15^{\circ} \mathrm{C}$ (dashed line) and $20^{\circ} \mathrm{C}$ (solid line) and $\mathbf{b}$ mucilage quantity effect on seedling development water base $\left(\Psi_{\mathrm{b}} \mathrm{S}\right)$ in $15^{\circ} \mathrm{C}$ (dashed line) and $20^{\circ} \mathrm{C}$ (solid line). GLM models were performed with the mean of three replicates for each accession for each species

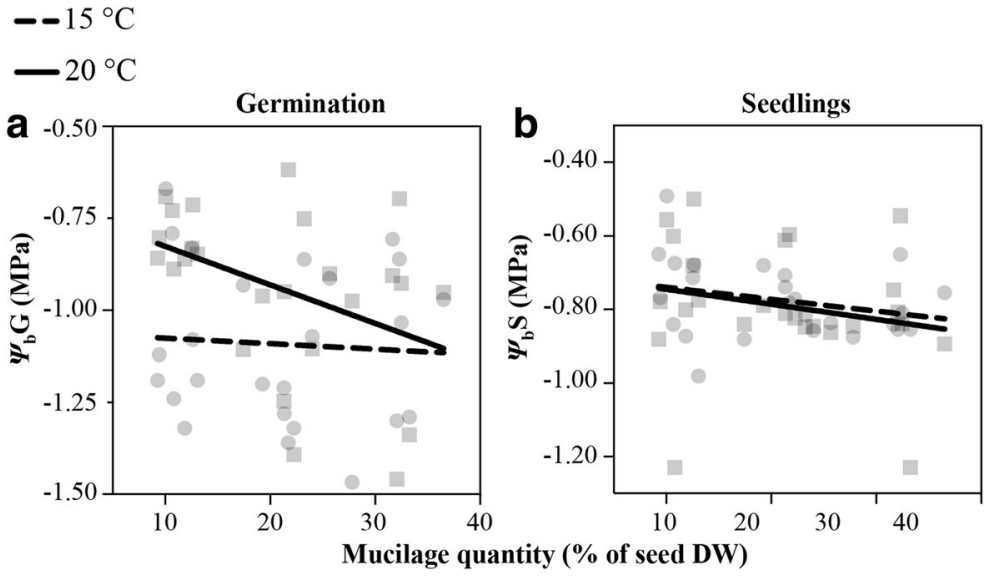


observations of high frequency of myxospermic plants in arid habitats (Grubert 1974; Ellner and Shmida 1981; Ryding 2001; Kreitschitz and Vallès 2007; Kreitschitz 2009).

Particularly P. coronopus and P. lanceolata revealed greater correlation with soil small pores (sgMC) (and adaptive capacity), as the soils from which they were harvested are less variable. Thus, when these soils (which are fixed in their character to exhibit smaller pore spaces) get wetted they might become significantly softer - presumably as a function of the mucilage. More arid conditions however increase the likelihood of seedlings being exposed to harder soils, as soil usually becomes harder as it dries. Indeed, our soil penetrometer tests at repacked DBD also show that the soil in this study has a tendency to dry harder at the same sMP compared with soils from less arid zones.

Soil strength is mostly affected by the soil water content and bulk density, (Vaz et al. 2001), and seedling developmental success may be highly influenced by both factors. The negative relationship of higher temperature, minimum and soil strength (sPR) parameter on Plantago germination at $20^{\circ} \mathrm{C}$ was shown to be dependent on collecting region/pedoclimatic conditions (Fig. $3 \mathrm{~d}$ and e), contrary to germination at $15^{\circ} \mathrm{C}$ (Fig. $3 b$ ) that showed positive correlation with all three variables and could in turn be related to lower soil surface resistance (Vaz et al. 2001). A study on two New Zealand native species commonly used in restoration programs; Cordyline australis (Agavaceae) and Leptospermum scoparium (Myrtaceae) showed improved establishment at an intermediate soil compaction level in the latter species while the former showed a development barrier at $-0.6 \mathrm{MPa}$ of soil strength (Bassett et al. 2005). Well-watered soils have lower soil strengths (Vaz et al. 2001 and this study) however we also observed that our soil samples increased penetrometer resistance when at the same gMP in samples from Andalusia (Fig. 1d), which had been exposed to lower precipitation and higher temperatures (Fig. 1e).

Although we have not tested how effective the seedlings are at overcoming soil strength directly, with our osmoticum tests we were able to overcome osmotic effects since osmotic potential is one element of plant traits required to overcome soil strength, since roots need to build up osmotic potential in order to overcome soil strength (Bengough et al. 2011). Previous germination work on three species of Cruciferae in relation to moisture stress showed clay as a substrate was in close agreement with that observed in polyethylene glycol solutions (Young et al. 1970). Our results showed that seedling root elongation negatively correlated with the soil strength (Fig. 3f and $\mathrm{j}$ ) that increases from to collecting sites with warmer pedoclimates (Fig. 1e). This reveals that soil penetration resistance could be one of the main constraints to seedling development in southern regions due its higher soil strength. A study of soil compaction on the occurrence of five Plantago species in coastal sand dunes in The Netherlands showed that the lowest percentages of emerged seedlings were found either on the soils with the highest degree of compaction $\left(10 \mathrm{~kg} / \mathrm{cm}^{2}\right)$ or on the moderately compacted soils $\left(5 \mathrm{~kg} / \mathrm{cm}^{2}\right)$ (Blom, 1976). The authors conclude that $P$. lanceolata is less adapted to mechanical resistance and $P$. coronopus seems to be more or less indifferent, which agrees with our results in these two species from the Andalusia region (Fig. S2e, f g and h).

The observed low correlation of soil gMC for germination and seedling radicle elongation (Fig. S3) may be associated with the mucilage quantity that, though it enhances the seed germination in the osmoticum range, especially at higher temperatures (Fig. 4b), seemed to be much more important for seedling development as demonstrated by the very strong correlations with seedling development (Fig. 4c and d). As discussed above, mucilage quantity revealed a negative correlation with minimum precipitation occurrence, although the mucilage quantity as a function of the water present in the small pore spaces showed positive effects on water retention, suggesting the importance of myxospermy on soil water retention (Fig. 2d). Deng et al. (2011) demonstrated that mucilage expansion of shepherd's purse seeds, hydrated in solutions of varying osmotic pressure, was $-0.54 \mathrm{MPa}$ and increased water retention, physical stability and reduced soil hydraulic conductivity that could explain our results of water pore spaces on mucilage expansion (Fig. 2c).

Several reports have shown that good contact between seed mucilage and the soil surface increases water absorption and boosts anchoring and germination. Thus, seeds of myxospermous species germinate more successfully on the soil surface, than non-myxospermic species (Bregman and Graven 1997; Zaady et al. 1997; van Oudtshoorn and van Rooyen 1999). In agreement, it was reported that the water held by the seed mucilage could serve as water reservoir for seedling establishment (Gutterman 1967; Gutterman and Shem-Tov 1994) that could explain our observed decrease in germination 
mortality (Fig. 4e and f), and presents a robust indication that seed mucilage has an important functional role in reducing seedling mortality under conditions of soil moisture deficit. This benefit seems to have its limits around $-0.8 \mathrm{MPa}$. Our observations agree with results using Artemisia sphaerocephala seedlings at shallow sand burial depths (Yang et al. 2012a). In another study with the same species the authors have shown the presence of mucilage (or its derivatives) in seedling tissues after growth using fluorescein isothiocyanate (FITC)labeled mucilage. Additionally, seed mucilage dissipation into the rooting medium promoted early seedling growth in barren sand dunes. These authors concluded that the seed mucilage can play an ecologically important role in the life cycles of plants especially in harsh arid environments (Yang et al. 2012b).

The base water potential for germination and seedling development is a critical parameter to predict germination periods for different species in a variety of environments (Bradford 1990; Welbaum et al. 1990; Guillemin et al. 2013; Dürr et al. 2015). Due to the seed mucilage capacity to retain water (Harper and Benton 1966; Fahn and Werker 1972; Young and Martens 1991; Huang et al. 2000; Penfield et al. 2001; Makouate et al. 2012; Deng et al. 2014) a positive influence was expected whereby seed mucilage quantity would lower the base water potential for seed germination and seedling root elongation under osmotic stress conditions. However, while it was observed that seeds with more mucilage had lower $\Psi_{\mathrm{b}} \mathrm{G}$ (Fig. 5a), this was only evident at $20^{\circ} \mathrm{C}$, indicative that such a protective germination capacity was only evident at higher temperatures. Seeds with high mucilage quantity did not have different $\Psi_{\mathrm{b}} \mathrm{S}$ at either temperature (Fig. 5b), which may relate to the higher seedling demand for water.

\section{Conclusion}

Our findings unveil how myxospermous seed mucilage quantity may determine seed germination, seedling survival and development under conditions of water-deficit stress. Seed mucilage quantity appeared as an 'adaptive' as opposed to 'species-specific' trait. We found that seeds with highest mucilage quantity were yielded by accessions localised in environments presenting: highest summer temperatures; lowest levels of summer precipitation; and soils which rendered soil water less accessible to plants, by virtue of their soil-pore structure.
Also, under conditions of water-deficit stress, seeds with most mucilage exhibited a lower base water potential for germination, suffered least seedling mortality and exhibited greatest seedling development.

Acknowledgements The research leading to these results has received funding from the People Programme (Marie Curie Actions) of the European Union's Seventh Framework Programme FP7/2007-2013/ under REA grant agreement $n^{\circ} 607785$. The Royal Botanic Gardens, Kew, receives grant-in-aid from Defra. The James Hutton Institute is supported by the Rural \& Environment Science \& Analytical Services Division of the Scottish Government. We are also grateful to Candido Galvez Ramirez (Semillas Silvestres), and Álvaro Bueno (Jardín Botánico Atlántico), for their valuable assistance in choosing the seed collecting sites. We also thank Matías Hernández González, Stephanie Frischie (Semillas Silvestres) and Eduardo Fernández Pascual (Royal Botanic Gardens, Kew) for their help in seed collecting.

Open Access This article is distributed under the terms of the Creative Commons Attribution 4.0 International License (http:// creativecommons.org/licenses/by/4.0/), which permits unrestricted use, distribution, and reproduction in any medium, provided you give appropriate credit to the original author(s) and the source, provide a link to the Creative Commons license, and indicate if changes were made.

\section{References}

Ahmad S, Ahmad R, Ashraf MY, Ashraf M, Waraich EA (2009) Sunflower (Helianthus annuus L.) response to drought stress at germination and seedling growth stages. Pak J Bot 41(2): 647-654

Ahmed MA, Kroener E, Holz M, Zarebanadkouki M, Carminati A (2014) Mucilage exudation facilitates root water uptake in dry soils. Funct Plant Biol 41(11):1129-1137

Bassett IE, Simcock RC, Mitchell ND (2005) Consequences of soil compaction for seedling establishment: implications for natural regeneration and restoration. Austral Ecol 30(8):827833

Bates D, Maechler M, Bolker B, Walker S (2014) lme4: linear mixed-effects models using Eigen and S4. R package version 1(7):1-23

Bengough AG, Mullins CE (1990) The resistance experienced by roots growing in a pressurised cell. A reappraisal. Plant Soil 123(1):73-78

Bengough AG, Mullins CE (1991) Penetrometer resistance, root penetration resistance and root elongation rate in two sandy loam soils. Plant Soil 131(1):59-66

Bengough AG, McKenzie BM, Hallett PD, Valentine TA (2011) Root elongation, water stress, and mechanical impedance: a review of limiting stresses and beneficial root tip traits. J Exp Bot 62(1):59-68

Blom CWPM (1976) Effects of trampling and soil compaction on the occurrence of some Plantago species in coastal sand 
dunes: I. Soil compaction, soil moisture and seedling emergence

Bradford KJ (1990) A water relations analysis of seed germination rates. Plant Physiol 94(2):840-849

Bregman R, Graven P (1997) Subcuticular secretion by cactus seeds improves germination by means of rapid uptake and distribution of water. Ann Bot 80(4):525-531

Carminati A, Moradi AB, Vetterlein D, Vontobel P, Lehmann E, Weller U, Vogel H-J, Oswald SE (2010) Dynamics of soil water content in the rhizosphere. Plant Soil 332(1-2):163176

Castroviejo S, Luceão M, Galán A, Jimenez-Mejías P, Cabezas F, Medina L (2009) Flora Iberica vol. XVIII PlantaginaceaeScrophulariaceae. Real Jardín Botánico, CSIC, Madrid

Cullen J (1975) Artemisia L. In: Flora of Turkey the East Aegean Islands, vol 5. University Press, Edinburg, pp 311-324

Deng W, Jeng DS, Toorop PE, Squire GR, Iannetta PP (2011) A mathematical model of mucilage expansion in myxospermous seeds of Capsella bursa-pastoris (shepherd's purse). Ann Bot 109(2):419-427

Deng W, Hallett PD, Jeng DS, Squire GR, Toorop PE, Iannetta PP (2014) The effect of natural seed coatings of Capsella bursapastoris L. Medik.(shepherd's purse) on soil-water retention, stability and hydraulic conductivity. Plant Soil 387(1-2): $167-176$

Dürr C, Dickie JB, Yang XY, Pritchard HW (2015) Ranges of critical temperature and water potential values for the germination of species worldwide: contribution to a seed trait database. Agric For Meteorol 200:222-232

Ellner S, Shmida A (1981) Why are adaptations for long-range seed dispersal rare in desert plants? Oecologia 51:133-144

Fahn A, Werker E (1972) Anatomical mechanisms of seed dispersal. In: Kozlowski TT (ed) Seed biology, Importance, Development, and Germination. Academic Press, London/ New York, pp 151-221

Grubert M (1974) Studies on the distribution of myxos- permy among seeds and fruits of Angiospermae and its ecological importance. Acta Biologica Venezuelica 8:315-551

Guillemin JP, Gardarin A, Granger S, Reibel C, Munier-Jolain N, Colbach N (2013) Assessing potential germination period of weeds with base temperatures and base water potentials. Weed Res 53(1):76-87. https://doi.org/10.1111/wre.12000

Gutterman Y (1967) Seed dispersal and germination in Blepharis persica (Burm.) Kuntze. Isr J Bot 16:213-234

Gutterman Y, Shem-Tov S (1994) Structure and function of the mucilaginous seed coats of Plantago coronopus inhabiting the Negev Desert of Israel. Isr J Plant Sci 44(2-3):125-133

Hardegree SP, Emmerich WE (1990) Partitioning water potential and specific salt effects on seed germination of four grasses. Ann Bot 66(5):587-595

Harper JL, Benton RA (1966) The behaviour of seeds in soil: II. The germination of seeds on the surface of a water supplying substrate. J Ecol:151-166

Hijmans RJ, Guarino L, Bussink C, Mathur P, Cruz M, Barrentes I, Rojas E (2004) Diva-Gis. Vsn. 5.0. A geographic information system for the analysis of species distribution data

Hijmans RJ, Cameron SE, Parra JL, Jones PG, Jarvis A (2005) Very high resolution interpolated climate surfaces for global land areas. Int J Climatol 25:1965-1978. https://doi. org/10.1002/joc. 1276
Huang Z, Gutterman Y (2000) Comparison of germination strategies of Artemisia ordosica with its two congeners from deserts of China and Israel. Acta Bot Sin 42(1):71-80

Josse J, Husson F (2016) missMDA: a package for handling missing values in multivariate data analysis. J Stat Softw 70:1-31

Koocheki A, Mortazavi SA, Shahidi F, Razavi SMA, Taherian AR (2009) Rheological properties of mucilage extracted from Alyssum homolocarpum seed as a new source of thickening agent. J Food Eng 91(3):490-496

Kreitschitz A (2009) Biological properties of fruit and seed slime envelope: how to live, fly, and not die. In: Gorb SN (ed) Functional surfaces in biology. Springer Science, New York, pp 11-30

Kreitschitz A, Vallès J (2007) Achene morphology and slime structure in some taxa of Artemisia L. and Neopallasia L.(Asteraceae). Flora 202(7):570-580

Kroener E, Zarebanadkouki M, Kaestner A, Carminati A (2014) Nonequilibrium water dynamics in the rhizosphere: how mucilage affects water flow in soils. Water Resour Res 50(8):6479-6495

Lobova TA, Mori SA, Blanchard F, Peckham H, CharlesDominique P (2003) Cecropia as a food resource for bats in French Guiana and the significance of fruit structure in seed dispersal and longevity. Am J Bot 90(3):388-403

Makouate HF, Van Rooyen MW, Van der Merwe CF (2012) Anatomy of myxospermic diaspores of selected species in the Succulent Karoo, Namaqualand, South Africa. Bothalia 42(1)

McCully ME, Boyer JS (1997) The expansion of maize root-cap mucilage during hydration. 3. Changes in water potential and water content. Physiol Plant 99(1):169-177

McFarlane HE, Gendre D, Western TL (2014) Seed coat ruthenium red staining assay. Bio Protoc 4(7):e1096

Metzger MJ (2018) The environmental stratification of Europe, [dataset]. University of Edinburgh. https://doi.org/10.7488 $/ \mathrm{ds} / 2356$

Penfield S, Meissner RC, Shoue DA, Carpita NC, Bevan MW (2001) MYB61 is required for mucilage deposition and extrusion in the Arabidopsis seed coat. Plant Cell 13(12):27772791

Ryding O (2001) Myxocarpy in the Nepetoideae (Lamia- ceae) with notes on mxyodiaspory in general. Syst Geogr Plants 71:502-514

Schat H (1981) Seed polymorphism and germination ecology of Plantago coronopus L. Acta Oecol Plant 2(4):367-380

Toorop PE, Campos-Cuerva R, Begg GS, Locardi B, Squire GR, Iannetta PP (2011) Co-adaptation of seed dormancy and flowering time in the arable weed Capsella bursa-pastoris (shepherd's purse). Ann Bot 109(2):481-489

Valentine TA, Hallett PD, Binnie K, Young MW, Squire GR, Hawes C, Bengough AG (2012) Soil strength and macropore volume limit root elongation rates in many UK agricultural soils. Ann Bot 110(2):259-270

van Oudtshoorn KVR, van Rooyen MW (1999) Restriction of dispersal due to reduction of dispersal structures. In: Dispersal biology of desert plants. Springer, Berlin/ Heidelberg, pp 93-119

Vaz CM, Bassoi LH, Hopmans JW (2001) Contribution of water content and bulk density to field soil penetration resistance as 
measured by a combined cone penetrometer-TDR probe. Soil Tillage Res 60(1):35-42

Watson KK (1966) An instantaneous profile method for determining the hydraulic conductivity of unsaturated porous materials. Water Resour Res 2(4):709-715

Welbaum GE, Tissaoui T, Bradford KJ (1990) Water relations of seed development and germination in muskmelon (Cucumis melo L.). Plant Physiol 92(4):1029-1037

Western TL (2012) The sticky tale of seed coat mucilages: production, genetics, and role in seed germination and dispersal. Seed Sci Res 22(1):1-25

Western TL, Skinner DJ, Haughn GW (2000) Differentiation of mucilage secretory cells of the Arabidopsis seed coat. Plant Physiol 122(2):345-356

Xu Z, Zhou G, Shimizu H (2010) Plant responses to drought and re-watering. Plant Signal Behav 5(6):649-654

Yang X, Dong M, Huang Z (2010) Role of mucilage in the germination of Artemisia sphaerocephala (Asteraceae) achenes exposed to osmotic stress and salinity. Plant Physiol Biochem 48(2-3):131-135

Yang X, Baskin JM, Baskin CC, Huang Z (2012a) More than just a coating: ecological importance, taxonomic occurrence and phylogenetic relationships of seed coat mucilage. Perspect Plant Ecol Evol Syst 14(6):434-442

Yang X, Baskin CC, Baskin JM, Zhang W, Huang Z (2012b) Degradation of seed mucilage by soil microflora promotes early seedling growth of a desert sand dune plant. Plant Cell Environ 35:872-883

Young JA, Evans RA (1973) Mucilaginous seed coats. Weed Sci 21(1):52-54

Young JA, Martens E (1991) Importance of hypocotyl hairs in germination of Artemisia seeds. J Range Manag:438-442

Young JA, Evans RA, Gifford RO, Eckert RE (1970) Germination characteristics of three species of Cruciferae. Weed Sci 18(1): $41-48$

Zaady E, Gutterman Y, Boeken B (1997) The germination of mucilaginous seeds of Plantago coronopus, Reboudia pinnata, and Carrichtera annua on cyanobacterial soil crust from the Negev Desert. Plant Soil 190(2):247-252

Publisher's note Springer Nature remains neutral with regard to jurisdictional claims in published maps and institutional affiliations. 